\section{Decision Support, Knowledge Representation and Management: A Balancing Act between Clinical Use and Implementation of Sophisticated Reasoning Techniques?}

\author{
Findings from the Section on Decision Support, Knowledge \\ Representation and Management
}

\author{
B. Brigl, Managing Editor for the IMIA Yearbook Section on Decision Support, Knowledge \\ Representation and Management \\ Friedrichsdorf, Germany
}

\section{Introduction}

On the one hand, the evaluation of existing clinical decision support systems concerning outcome and influence on medical decisions is one major topic [1]. As Coiera stated in [2] the use of clinical decision support systems can improve the quality of healthcare, but also introduce machine-related error. This problem is e.g. also addressed in the paper of Koppel et al. [2] or Han et al. [3] and picked-up systematically by Ammenwerth et al. [5], who as consequence ask for evaluation guidelines. On the other hand, as Peleg et al. stated in [6], the gradual maturation of knowledge representation and reasoning formalisms as well as of electronic health record systems offers new possibilities to implement and integrate clinical decision support systems.

\section{Best Paper Selection}

The best paper selection process stands in the tradition of the IMIA yearbooks of the years before [7], [8]. As result of a comprehensive reviewing process, four excellent papers (see Table 1) were selected for the section 'Decision Support, Knowledge Representation and Management'. A brief content summary of the selected best papers can be found in the appendix of this paper.

The situation described in the introduction is reflected by the best paper selection for the IMIA Yearbook 2007. The section includes as well evaluation papers and papers introducing new reasoning methods. McGregor et al. [9] demonstrate in their randomized controlled trial that the usage of a clinical decision support system leads to substantial saving of antimicrobial expenditures and time savings. Maviglia et al. [10] show that a medication information button integrated to the electronic medical record answered more than $83 \%$ of the queries satisfactorily and that in about $15 \%$ of the cases the use significantly altered a medical decision. On the basis of penetrating injuries of the heart, Rubin et al. [11] illustrate the integration of ontological knowledge and patient-specific geometrical data to assess and triage injured patients. Bellazzi et al [12] describe an approach to improve quality management in hemodialysis services using temporal data mining techniques 
Table 1 Best paper selection of articles for the IMIA Yearbook of Medical Informatics 2007 in the section 'Decision Support, Knowledge Representation and Management'. The articles are listed in alphabetical order of the first author's surname.

\section{Section}

Decision Support, Knowledge Representation and Management

- Bellazzi R, Larizza C, Magni P, Bellazzi R. Temporal data mining for the quality assessment of hemodialysis services. Artif Intell Med 2005;34:25-39.

- Maviglia SM, Yoon CS, Bates DW, Kuperman G. Knowledgelink: impact of context-sensitive information retrieval on clinicians' information needs. J Am Med Inform Assoc 2006;13:67-73.

- McGregor JC, Weekes E, Forrest GN, Standiford HC, Perencevich EN, Furuno JP, Harris AD. Impact of a computerized Clinical Decision Support System on Reducing Inappropriate Antimicrobial Use: A Randomized Controlled Trial. J Am Med Inform Assoc 2006;13:378-84

- Rubin DL, Dameron O, Bashir Y, Grossman D, Dev P, Musen MA. Using ontologies linked with geometric models to reason about penetrating injuries. Artif Intell Med 2006;37:167-76.

\section{Conclusions and Outlook}

The best paper selection for the IMIA Yearbook 2007 section 'decision support, knowledge representation and management' concentrates on two major problems that are in the focus of current research: the clinical evaluation of decision support systems and the development of new reasoning methods. As stated in the IMIA Yearbook 2006 [13], the selection again shows the broad methodological spectrum in this field. But particularly, the selection supports three main conclusions:

- There is still a very deep gap between rather small decision support solutions- regardless whether they are integrated in an electronic health record or are used as stand-alone systems - which are evaluated successfully in clinical environments and more complex decision support systems using sophisticated representation and reasoning techniques, but lack of clinical use.

- Today the implementation of decision support systems benefits from research done in the last decades: there are mature ontologies [14] like the Foundational Model of Anatomy available, used e.g. [11], reasoning techniques e.g. for data mining are well investigated and ready for use [12], and electronic health records can delivery patientspecific data necessary for decision support.

- Research on clinical guidelines [15] and natural language processing that dominated a long time the research community seems to be in a phase of reorientation.

Up-to-date information about current and future issues of the IMIA Yearbook is available at http://www.schattauer.de/ index.php?id=1384.

\section{Acknowledgement}

We greatly acknowledge the support of Martina Hutter and of the reviewers in the selection process of the IMIA yearbook

\section{References}

1. Rigby M. Evaluation - The Cinderella Science of ICT in Health. In: Haux R, Kulikowski C, editors. IMIA Yearbook of Medical Informatics 2006. Methods Inf Med 2006; 45 Suppl 1:114-20.

2. Coiera E, Westbrook J, Wyatt J. The safety and quality of decision support systems. Methods Inf Med 2006;45 Suppl 1:20-5.

3. Koppel R, Metlay JP, Cohen A, Abaluck B, Localio AR, Kimmel SE, et al. Role of computerized physician order entry systems in facilitating medication errors. JAMA 2005 Mar 9;293(10):1197-203.

4. Han YY, Carcillo JA, Venkataraman ST, Clark RS, Watson RS, Nguyen TC, et al. Unexpected increased mortality after implementation of a commercially sold computerized physician order entry system. Pediatrics 2005 Dec;116(6):1506-12. Erratum in: Pediatrics. 2006 Feb;117(2):594.

5. Ammenwerth E, Talmon J, Ash JS, Bates DW,
Beuscart-Zephir MC, Duhamel A, et al. Impact of CPOE on mortality rates - contradictory findings, important messages. Methods Inf Med. 2006; 45(6):586-93.

6. Peleg M, Tu S. Decision Support, Knowledge Representation and Management in Medicine. In: Haux $\mathrm{R}$, Kulikowski C, editors. IMIA Yearbook of Medical Informatics 2006. Methods Inf Med 2006; 45 Suppl 1:72-80.

7. Haux R, Kulikowski C, editors. IMIA Yearbook of Medical Informatics 2006. Methods Inf Med.2006; 45 Suppl 1:124-35.

8. Bott OJ, Ammenwerth E, Brigl B, Knaup P, Lang $\mathrm{E}$, Pilgram R, et al. The challenge of ubiquitous computing in health care: technology, concepts and solutions. Findings from the IMIA Yearbook of Medical Informatics 2005. Methods Inf Med 2005;44:473-9.

9. McGregor JC, Weekes E, Forrest GN, Standiford HC, Perencevich EN, Furuno JP, et al. Impact of a computerized Clinical Decision Support System on Reducing Inappropriate Antimicrobial Use: A Randomized Controlled Trial. J Am Med Inform Assoc 2006; 13:378-84.

10. Maviglia SM, Yoon CS, Bates DW, Kuperman G. KnowledgeLink: impact of context-sensitive information retrieval on clinicians' information needs. J Am Med Inform Assoc 2006;13:67-73.

11. Rubin DL, Dameron O, BashirY et al. Using ontologies linked with geometric models to reason about penetrating injuries. Artif Intell Med 2006; 37:167-76.

12. Bellazzi R, Larizza C, Magni P, Bellazzi R. Temporal data mining for the quality assessment of hemodialysis services. Artif Intell Med 2005;34: 25-39.

13. Brigl B. Decision Support, Knowledge Representation and Management: A broad methodological spectrum. In: Haux R, Kulikowski C, editors. IMIA Yearbook of Medical Informatics 2006. Methods Inf Med 2006; 45 Suppl 1:81-3

14. Cimino JJ, Zhu X. The Practical Impact of Ontologies on Biomedical Informatics. In: Haux R, Kulikowski C (eds). IMIA Yearbook of Medical Informatics 2006. Methods Inf Med 2006; 45 Suppl 1:124-35.

15. Peleg M, Tu S, Bury J, Ciccarese P, Fox J, Greenes RA, Hall R, Johnson PD, Jones N, Kumar A, Miksch S, Quaglini S, Seyfang A, Shortliffe EH, Stefanelli M. Comparing computer-interpretable guideline models: a case-study approach. J Am Med Inform Assoc 2003;10(1):52-68.

Correspondence to:

Dr. Birgit Brigl

Kapersburgstr. 40

D-61381 Friedrichsdorf

Germany

Tel: +496175798598

Fox: +496175 798597

E-mail: birgit.brigl@t-online.de 


\section{Appendix: Content Summa- ries of Selected Best Papers for the IMIA Yearbook 2007, Section Decision Support, Knowledge Representation and Management}

\section{Bellazzi R, Larizza C, Magni P, Bellazzi R \\ Temporal data mining for the quality assessment of hemodialysis services}

\section{Artif Intell Med 2005;34:25-39}

Bellazzi et al [12] describe an approach to improve quality management in hemodialysis services using temporal data mining techniques. The approach is based on time series automatically collected during hemodialysis sessions. They introduce two new methods to discover association rules and temporal rules in order to detect unsatisfactory clinical results. These methods base on data reduction, data reduction, multi-scale filtering and temporal abstraction techniques. With these methods 5800 dialysis sessions coming from 43 patients were analysed. The resulting qualitative rules were assessed by domain experts to distinguish rules confirming available background knowledge, and unexpected but plausible rules.

\section{Maviglia SM, Yoon CS, Bates DW, Kuperman G}

KnowledgeLink: impact of context-sensitive information retrieval on clinicians' information needs

\section{J Am Med Inform Assoc 2006;13:67-73}

In their paper, Maviglia et al. [10]

\footnotetext{
The complete papers can be accessed in the Yearbook's full electronic version, provided that permission has been granted by the copyright holder(s)
}

wanted to answer the question of how effective knowledge links integrated in an electronic patient record are, and how the use affects the medical decision making. For that purpose, they developed an information button called KnowledgeLink, to provide contextsensitive and patient-specific links from medications directly into the relevant sections of one of two knowledge resources. The study lasted one year, during which time data were collected about frequency of use and demographics of the users, patients, and drugs that were queried. During the study users were periodically asked to answer short questionnaires. At the end of the study, they were asked to complete a more comprehensive survey. The study could show that although the KnowledgeLink was used quite infrequently and for brief sessions, more than $83 \%$ of the queries were satisfactorily answered and in about $15 \%$ of the cases the use of KnowledgeLink significantly altered a medical decision.

\section{McGregor JC, Weekes E, Forrest GN, Standiford HC, Perencevich EN, Furuno JP, Harris AD \\ Impact of a computerized Clinical Decision Support System on Reducing Inappropriate Antimicrobial Use: A Randomized Controlled Trial}

\section{J Am Med Inform Assoc 2006; 13:378-84}

An excellent example of how clinical decision support systems can improve medical care is given in [9]. McGregor et al. present a randomized controlled trial, to assess the impact of a decision support system on reducing inappropriate antimicrobial use. The decision support system (DSS) was designed as an alerting system that created a list of patients which potentially require a change in their current antimicrobial therapy. Antimicrobial use was man- aged by an existing antimicrobial intervention team (AMT) using the (DSS) in the intervention arm, and without the DSS in the control arm. Outcomes assessed were hospital antimicrobial costs, mortality, length of hospitalization and time spent managing antimicrobial utilization. The study showed that usage of the DSS led to substantial saving of antimicrobial expenditures and time savings for the AMT. There was no significant difference observed in mortality.

\section{Rubin DL, Dameron 0, Bashir Y Grossman D, Dev P, Musen MA}

Using ontologies linked with geometric models to reason about penetrating injuries

\section{Artif Intell Med 2006;37:167-76}

On the basis of penetrating injuries of the heart, Rubin et al. [11] illustrate the integration of ontological knowledge and patient-specific geometrical data to assess and triage injured patients. As ontological knowledge sources they used the Digital Anatomist Foundational Model of Anatomy (FMA) representing morphology and composition of anatomic structures and an ontology of coronary artery anatomy and regional myocardial perfusion. In their approach, the regions of a three-dimensional geometric model derived from segmented images were mapped to the ontological concepts. Two reasoning services were implemented: the first one determines which organs are injured by the penetrating injury; the second one determines whether any vital structures are injured and deduced the consequences of such an injury. The methods were tested on data of the Visible Human. 